\title{
REDUCING TRANSMITTED POWER OF MOVING RELAY NODE IN LONG-TERM EVOLUTION-ADVANCED CELLULAR NETWORKS
}

\author{
${ }^{1,2}$ Jaafar A. Aldhaibani, ${ }^{1}$ A. Yahya, ${ }^{1}$ R.B. Ahmad, ${ }^{1}$ Rashid A. Fayadh and ${ }^{2}$ Ameer H. Abbas \\ ${ }^{1}$ School of Computer and Communication Engineering, University Malaysia Perlis, 01000, Kangar, Perlis, Malaysia \\ ${ }^{2}$ Ministry of Science and Technology, Baghdad, Iraq
}

Received 2013-08-03; Revised 2014-02-01; Accepted 2014-02-03

\begin{abstract}
Wireless multi-hop relay networks have become very significant technologies in mobile communications. These networks ensure data rate transfer and coverage extension with a low cost. In this study two types of relay are studied; Fixed Relay Node (FRN) and Moving Relay Node (MRN). Where system analyses for uplink and downlink transmission are derived in this study. Moreover the optimal relay location of FRN was proposed to provide a maximum achievable rate at user in cell edge region. Finally, a new algorithm was suggested to balance and control on the transmitted power of MRN over cell size to provide the required SNR and throughput at the users inside vehicle with reducing the consumption transmitted relay power. Numerical results indicate an enhancement in received signal strength for users at the cell edge from (-90 to -65$) \mathrm{dBm}$ and $40 \%$ increment from all cell size after deploying FRN at proposed locations. As well as, the results revealed that there is saving nearly $75 \%$ from transmitted power in MRN after using proposed algorithm. ATDI simulator was used to verify the numerical results, which deals with real digital cartographic and standard formats for terrain.
\end{abstract}

Keywords: LTE-A, Fixed Relay Node, Moving Relay Node, Coverage

\section{INTRODUCTION}

Long-Term Evolution-Advanced (LTE-A) is the enhancing of the 3rd Generation Partnership Project (3GPP) LTE, which is improves LTE features in terms of coverage and throughput (Jaafar et al., 2013; Kumaran et al., 2013). The relay is one of the major innovations of LTE-A, which extends the coverage and enhances throughput at the users within cell size. The basic idea of relaying is that the relay received the signals from source and forwarded these signal after amplification to the destination node.

On relaying scenarios, there are two types of relaying architectures: Fixed Relay Node (FRN) and Moving Relay Node (MRN). Where FRNs are deployed near cell edge to increase the coverage and enhancing the throughput at the users in this region. However, this improvement in coverage and throughput based on the relay placement which is provides fairness distribution of coverage within cell size as shown in Fig. 1.

MRN is same kind of functionality than the FRN but with the difference that they offer it while moving with the users. MRN is new innovation to improve the throughput for vehicular users at LTE-A networks where it can be deployed flexibly to increase the throughput for passengers in buses or trains over rural area in cases where FRNs are not available or not economically justifiable and the weak received signal from BSs (Bulakci, 2012; Gandhi and Narayanasamy, 2011).

MRN is installed on vehicle and connected wirelessly with the BS via relay link and with passengers via access links, so the MRN and passenger are called group mobility (Peters and Heath, 2009) as shown in Fig. 1. In fact, group mobility can be provided anywhere a large number of users are moving together during is using cellular network services.

Corresponding Author: Jaafar A. Aldhaibani, School of Computer and Communication Engineering, University Malaysia Perlis, 01000, Kangar, Perlis, Malaysia 


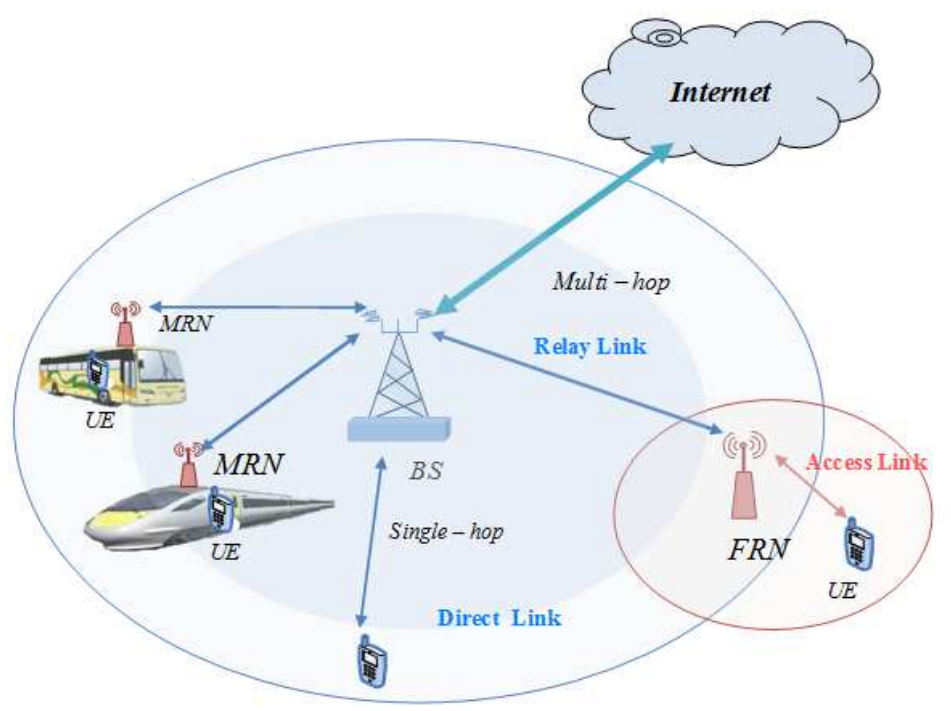

Fig. 1. Relay nodes scenarios

The MRN makes these services more reliable, with the assumption that the relay link has a much better channel than regular UEs. The relay link antennas are high and thus have fewer obstacles in the path of the radio waves than regular UE-antenna (Katiyar and Bhattacharjee, 2010).

Moving relays are connected to external power source via a battery charger or have their own power supply unit. This allows MRNs to have a relatively high access to processing capabilities and to constant higher transmission powers.

Using MRN in cellular systems is still under discussion in the 3GPP LTE (Sui et al., 2012). Studies have shown that through deploying symmetrical and cooperative relays on top of trains, the Quality-ofService (QoS) of a UE inside the vehicle can be significantly improved.

Most promising MRN such as relays on trains have a high capacity of passengers and most of them use mobile service and some even mobile broadband through movement.

Each car in the train can be installed with its individual relay node and these relay nodes can be interconnected with each other. The number of relay based on the relay node capability infrastructure. One of the key which is making the design of the MRN in trains simpler is the fact that the train movement can be predicted great easily. The train track information can be made available to the LTE-A-network (Prabha et al., 2014).

The rest of the paper is organized as follows: Section 2 presents the description of proposed system mode with deriving of the multi-user of both FRN and MRN. section 3 explains the Balancing Algorithm of transmitted power of MRN. Section 4 discusses the results and section 5 is the conclusion.

\section{MATERIALS AND METHODS}

Half Duplex (HD) transmission mode at the relay node proposed in this scheme as shown in Fig. 2, where in general the received signal at each node is explained by (Sadek et al., 2010; Siraj and Bakar, 2012) Equation (1):

$\mathrm{Y}=\mathrm{HX}+\mathrm{n}$

where, $\mathrm{X}$ is the transmitted symbol from $\mathrm{BS}, \mathrm{H}$ is the coefficient channel between the source and the destination and $\mathrm{n}$ is the AWGN in the corresponding channels with variance $\sigma_{\mathrm{o}}$ i.e., $\mathrm{n} \sim \mathrm{CN}\left(0, \sigma_{\mathrm{o}}\right)$. Therefore the system performance could be explained by two schemes, fixed and mobility schemes.

\subsection{Fixed Node Scheme}

In this scheme all nodes; BS, FRN and UEq, are as fixed as where set of $\mathrm{UEq}$ is $\mathrm{Q}=\left\{\mathrm{UE}_{1}, \mathrm{UE}_{2}, \ldots, \mathrm{UE}_{\mathrm{q}}\right\}$. The relay in HD mode cannot simultaneously transmit and receive. Thus, in time slot $\left[\mathrm{t}_{1}\right]$ the relay receives information from both the BS and UEs, as shown in Fig. 2. Therefore the received signal, $\mathrm{y}_{\mathrm{NR}}\left[\mathrm{t}_{1}\right]$ can be written as Equation (2):

$$
\mathrm{y}_{\mathrm{RN}}\left[\mathrm{t}_{1}\right]=\mathrm{H}_{\mathrm{A}} \mathrm{X}\left[\mathrm{t}_{1}\right]+\sum_{\mathrm{q}=1}^{\mathrm{Q}} \mathrm{H}_{\mathrm{B}, \mathrm{q}} \mathrm{X}\left[\mathrm{t}_{1}\right]+\mathrm{n}_{\mathrm{RN}}
$$




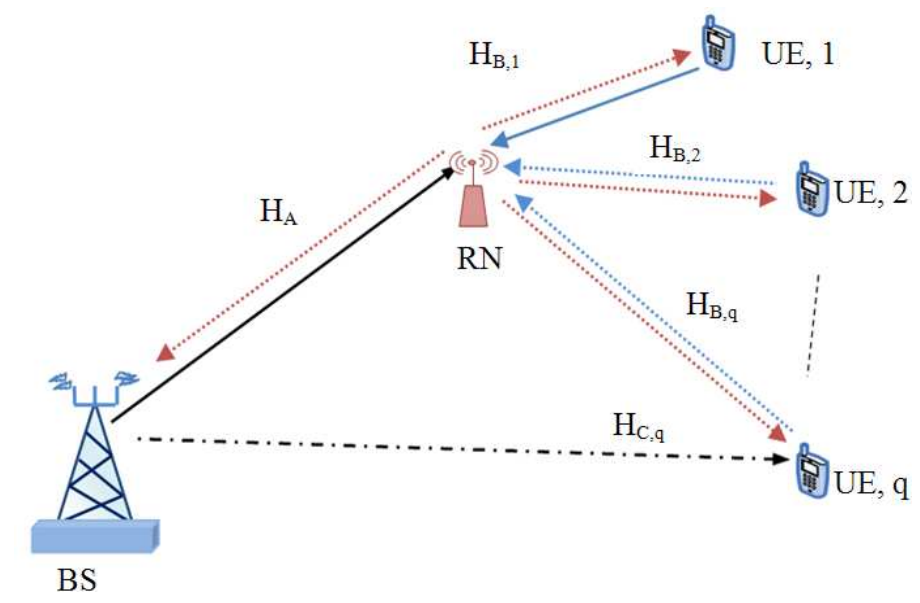

Fig. 2. Half duplex multi user system

where, $q=1,2,3 \ldots \mathrm{Q}, \mathrm{Q}$ is the total number of UE and $\mathrm{n}_{\mathrm{RN}}$ is the AWGN with variance $\sigma_{0}$ as well as, the received signal at UE from BS via a direct link is Equation (3):

$\mathrm{y}_{\mathrm{UE}, \mathrm{q}}\left[\mathrm{t}_{1}\right]=\mathrm{H}_{\mathrm{C}, \mathrm{q}} \mathrm{X}\left[\mathrm{t}_{1}\right]+\mathrm{n}_{\mathrm{UE}}\left[\mathrm{t}_{1}\right]$

While at the second slot $\left[\mathrm{t}_{2}\right]$, the BS and UEq receives the amplified signals transmitted from FRN as $\mathrm{X}_{\mathrm{RN}}\left[\mathrm{t}_{2}\right]$, with amplification factor $\Psi$. In order to evaluate the value of this amplification factor, the signals in/out of relay will be derived, as following equations.

Firstly, for simplified let system consisted from FRN, $\mathrm{UE}$ and $\mathrm{BS}$ and all noise is equally, where $\mathrm{n}_{\mathrm{RN}}=\mathrm{n}_{\mathrm{UE}}=$ $\mathrm{n}_{\mathrm{BS}}=\mathrm{No}$, therefore the received signals in relay at first time slot $\mathrm{t} 1$ is:

$$
\mathrm{y}_{\mathrm{RN}}\left[\mathrm{t}_{1}\right]=\mathrm{H}_{\mathrm{A}} \mathrm{X}_{\mathrm{i}}\left[\mathrm{t}_{1}\right]+\mathrm{H}_{\mathrm{B}} \mathrm{X}_{\mathrm{UE}}\left[\mathrm{t}_{1}\right]+\mathrm{N}_{\mathrm{o}}
$$

Then the output signal from relay after amplification is Equation (5a and b):

$$
\mathrm{X}_{\mathrm{RN}}\left[\mathrm{t}_{2}\right]=\Psi \mathrm{y}_{\mathrm{RN}}\left[\mathrm{t}_{1}\right]+\mathrm{N}_{\mathrm{o}}
$$

By substation Equation (4), the resulting is:

$$
\mathrm{X}_{\mathrm{RN}}\left[\mathrm{t}_{2}\right]=\Psi\left(\mathrm{H}_{\mathrm{A}} \mathrm{X}_{\mathrm{i}}\left[\mathrm{t}_{1}\right]+\mathrm{H}_{\mathrm{B}} \mathrm{X}_{\mathrm{UE}}\left[\mathrm{t}_{1}\right]+\mathrm{N}_{\mathrm{o}}\right)
$$

Taking Expectation function for two sides (Rizinski and Kafedziski, 2011) Equation (6 to 10):

$$
\mathrm{E}\left|\mathrm{X}_{\mathrm{RN}}\left[\mathrm{t}_{2}\right]\right|^{2}=\mathrm{E}\left|\Psi\left(\mathrm{H}_{\mathrm{A}} \mathrm{X}_{\mathrm{i}}\left[\mathrm{t}_{1}\right]+\mathrm{H}_{\mathrm{B}} \mathrm{X}_{\mathrm{UE}}\left[\mathrm{t}_{1}\right]+\mathrm{N}_{\mathrm{o}}\right)\right|^{2}
$$

$$
\begin{aligned}
& \mathrm{P}_{\mathrm{RN}}=\Psi^{2}\left[\mathrm{E}\left|\mathrm{H}_{\mathrm{A}} \mathrm{X}_{\mathrm{i}}\left[\mathrm{t}_{1}\right]\right|^{2}+\mathrm{E}\left|\mathrm{H}_{\mathrm{B}} \mathrm{X}_{\mathrm{UE}}\left[\mathrm{t}_{1}\right]\right|^{2}+\mathrm{E}\left|\mathrm{N}_{\mathrm{o}}\right|^{2}\right] \\
& \mathrm{P}_{\mathrm{RN}}=\Psi^{2}\left[\left|\mathrm{H}_{\mathrm{A}}\right|^{2} \mathrm{E}\left|\mathrm{X}_{\mathrm{i}}\left[\mathrm{t}_{1}\right]\right|^{2}+\left|\mathrm{H}_{\mathrm{B}}\right|^{2} \mathrm{E}\left|\mathrm{X}_{\mathrm{UE}}\left[\mathrm{t}_{1}\right]\right|^{2}+\mathrm{E}\left|\mathrm{N}_{\mathrm{o}}\right|^{2}\right] \\
& \mathrm{P}_{\mathrm{RN}}=\Psi^{2}\left[\left|\mathrm{H}_{\mathrm{A}}\right|^{2} \mathrm{P}_{\mathrm{i}}+\left|\mathrm{H}_{\mathrm{B}}\right|^{2} \mathrm{P}_{\mathrm{UE}}+\mathrm{E}\left|\mathrm{N}_{\mathrm{o}}\right|^{2}\right] \\
& \Psi=\sqrt{\frac{\mathrm{P}_{\mathrm{RN}}}{\left|\mathrm{H}_{\mathrm{A}}\right|^{2} \mathrm{P}_{\mathrm{i}}+\left|\mathrm{H}_{\mathrm{B}}\right|^{2} \mathrm{P}_{\mathrm{UE}}+\mathrm{N}_{\mathrm{o}}}}
\end{aligned}
$$

To study the performance of system in detail, the uplink and downlink performance must be analysis, so the uplink transmitted signal from the relay to the Base Station (BS) can be represented as:

$\mathrm{y}_{\mathrm{BS}}\left[\mathrm{t}_{2}\right]=\Psi \mathrm{H}_{\mathrm{A}} \mathrm{y}_{\mathrm{RN}}\left[\mathrm{t}_{1}\right]+\mathrm{n}_{\mathrm{BS}}$

By substitution Equation (2) in Equation (11), the resulting is:

$\mathrm{y}_{\mathrm{BS}}\left[\mathrm{t}_{2}\right]=\Psi\left[\mathrm{H}_{\mathrm{A}} \mathrm{X}\left[\mathrm{t}_{1}\right]+\left(\sum_{\mathrm{q}=1}^{\mathrm{Q}} \mathrm{H}_{\mathrm{B}, \mathrm{q}} \mathrm{X}_{\mathrm{q}}\left[\mathrm{t}_{1}\right]\right)+\mathrm{n}_{\mathrm{RN}}\right]+\mathrm{n}_{\mathrm{BS}}$

At the uplink the BS receives two signals; via relay link and direct link, then the BS combines these signals from multi users and relay, therefore the Equation (12) will be as Equation (13):

$$
\begin{aligned}
& \mathrm{y}_{\mathrm{BS}}\left[\mathrm{t}_{2}\right]=\left(\sum_{\mathrm{q}=1}^{\mathrm{Q}} \mathrm{H}_{\mathrm{B}, \mathrm{q}} \mathrm{X}_{\mathrm{q}}\left[\mathrm{t}_{2}\right]\right)+ \\
& \Psi \mathrm{H}_{\mathrm{A}} \mathrm{H}_{\mathrm{A}} \mathrm{X}\left[\mathrm{t}_{1}\right]+\left(\Psi \mathrm{H}_{\mathrm{A}} \sum_{\mathrm{q}=1}^{\mathrm{Q}} \mathrm{H}_{\mathrm{B}, \mathrm{q}} \mathrm{X}_{\mathrm{q}}\left[\mathrm{t}_{1}\right]\right)+\Psi \mathrm{H}_{\mathrm{A}} \mathrm{n}_{\mathrm{RN}}+\mathrm{n}_{\mathrm{BS}}
\end{aligned}
$$


While downlink received signal at each q-UE via relay and direct link can be represented as:

$$
\mathrm{y}_{\mathrm{UE}, \mathrm{q}}\left[\mathrm{t}_{2}\right]=\mathrm{H}_{\mathrm{C}, \mathrm{q}} \mathrm{X}\left[\mathrm{t}_{2}\right]+\Psi \mathrm{H}_{\mathrm{B}, \mathrm{q}} \mathrm{y}_{\mathrm{RN}}\left[\mathrm{t}_{1}\right]+\mathrm{n}_{\mathrm{UE}}
$$

By substitution Equation (2) in Equation (14), the result is Equation (15):

$$
\begin{aligned}
& \mathrm{y}_{\mathrm{UE}, \mathrm{q}}\left[\mathrm{t}_{2}\right]=\mathrm{H}_{\mathrm{C}, \mathrm{q}} \mathrm{X}\left[\mathrm{t}_{2}\right]+\Psi \mathrm{H}_{\mathrm{A}} \mathrm{H}_{\mathrm{B}, \mathrm{q}} \mathrm{X}\left[\mathrm{t}_{2}\right]+ \\
&\left(\Psi \mathrm{H}_{\mathrm{B}, \mathrm{q}} \mathrm{H}_{\mathrm{B}, \mathrm{q}} \mathrm{X}\left[\mathrm{t}_{2}\right]\right)+\Psi \mathrm{H}_{\mathrm{B}, \mathrm{q}} \mathrm{n}_{\mathrm{RN}}+\mathrm{n}_{\mathrm{UE}}
\end{aligned}
$$

Each source node processes and cancels the selfinterface term from the received signal (Chun and Park, 2012). Therefore, the resulting signals at BS and $\mathrm{UE}_{\mathrm{q}}$ can be rewritten as Equation (16):

$$
\begin{aligned}
& \hat{\mathrm{y}}_{\mathrm{BS}}\left[\mathrm{t}_{2}\right]=\left(\sum_{\mathrm{q}=1}^{\mathrm{Q}} \mathrm{H}_{\mathrm{C}, \mathrm{q}} \mathrm{X}_{\mathrm{q}}\left[\mathrm{t}_{2}\right]\right)+ \\
& \left(\Psi \mathrm{H}_{\mathrm{A}} \sum_{\mathrm{q}=1}^{\mathrm{Q}} \mathrm{H}_{\mathrm{B}, \mathrm{q}} \mathrm{X}_{\mathrm{q}}\left[\mathrm{t}_{1}\right]\right)+\Psi \mathrm{H}_{\mathrm{A}} \mathrm{n}_{\mathrm{RN}}+\mathrm{n}_{\mathrm{BS}}
\end{aligned}
$$

In addition, the signal at each q-user can be expressed as Equation (17):

$$
\widehat{\mathrm{y}}_{\mathrm{UE}, \mathrm{q}}\left[\mathrm{t}_{2}\right]=\mathrm{H}_{\mathrm{C}, \mathrm{q}} \mathrm{X}\left[\mathrm{t}_{2}\right]+\Psi \mathrm{H}_{\mathrm{A}} \mathrm{H}_{\mathrm{B}, \mathrm{q}} \mathrm{X}\left[\mathrm{t}_{2}\right]+\Psi \mathrm{H}_{\mathrm{B}, \mathrm{q}} \mathrm{n}_{\mathrm{RN}}+\mathrm{n}_{\mathrm{UE,q}}
$$

Assuming that the noise at all sources is equal No $n_{R N}$ $=\mathrm{n}_{\mathrm{BS}}=\mathrm{n}_{\mathrm{UE}}=\mathrm{N}_{\mathrm{O}}$, based on the above analysis, we can evaluate the instantaneous SNR in two ways (downlink and uplink) respectively as follows Equation (18 and 19):

$$
\begin{aligned}
& \rho_{\mathrm{UE}, \mathrm{q}}=\frac{\mathrm{P}_{\mathrm{BS}}\left|\mathrm{H}_{\mathrm{C}, \mathrm{q}}\right|^{2}}{\mathrm{~N}_{\mathrm{O}}}+\frac{\Psi^{2} \mathrm{P}_{\mathrm{BS}}\left|\mathrm{H}_{\mathrm{A}}\right|^{2}\left|\mathrm{H}_{\mathrm{B}, \mathrm{q}}\right|^{2}}{\left(\Psi^{2}\left|\mathrm{H}_{\mathrm{B}, \mathrm{q}}\right|^{2}+1\right) \mathrm{N}_{\mathrm{O}}} \\
& \rho_{\mathrm{BS}}=\frac{\sum_{\mathrm{q}=1}^{\mathrm{Q}} \mathrm{P}_{\mathrm{UE}}\left|\mathrm{H}_{\mathrm{C}, \mathrm{q}}\right|^{2}}{\mathrm{~N}_{\mathrm{O}}}+\frac{\Psi^{2} \mathrm{P}_{\mathrm{UE}}\left|\mathrm{H}_{\mathrm{A}}\right|^{2} \sum_{\mathrm{q}=1}^{\mathrm{Q}}\left|\mathrm{H}_{\mathrm{B}, \mathrm{q}}\right|^{2}}{\left(\Psi^{2}\left|\mathrm{H}_{\mathrm{A}}\right|^{2}+1\right) \mathrm{N}_{\mathrm{O}}}
\end{aligned}
$$

Inserting Equation (10) in Equation (18), we can get the instantaneous SNR at $\mathrm{UE}_{\mathrm{q}}$ as Equation (20):

$$
\rho_{\mathrm{UE}, \mathrm{q}}=\frac{\mathrm{P}_{\mathrm{i}}\left|\mathrm{H}_{\mathrm{C}, \mathrm{q}}\right|^{2}}{\mathrm{~N}_{\mathrm{O}}}+\frac{\mathrm{P}_{\mathrm{i}} \mathrm{P}_{\mathrm{RN}}\left|\mathrm{H}_{\mathrm{A}}\right|^{2}\left|\mathrm{H}_{\mathrm{k}, \mathrm{q}}\right|^{2}}{\left[\mathrm{P}_{\mathrm{i}}\left|\mathrm{H}_{\mathrm{A}}\right|^{2}+2 \mathrm{P}_{\mathrm{RN}}\left|\mathrm{H}_{\mathrm{k}, \mathrm{q}}\right|^{2}+\mathrm{N}_{\mathrm{O}}\right] \mathrm{N}_{\mathrm{O}}}
$$

The achievable bit rates of the multi-hop node at each $\mathrm{q}^{\text {th }}$-user is represented as Equation (21):

$$
\mathrm{R}_{\mathrm{UE}, \mathrm{q}}=\frac{1}{2} \log _{2}\left(1+\rho_{\mathrm{UE}, \mathrm{q}}\right)
$$

\subsection{Optimum Relay Location at Cell}

Outage is defined as the event in which the received signal to noise ration SNR falls below a certain threshold $\rho_{\text {th }}$ The received signals at relay via relay and access links are expressed as the following Equation (22 and 23):

$$
\begin{aligned}
& Y_{i, R L}=H_{A} X\left[t_{1}\right]+N_{o} \\
& Y_{R N, U E}=H_{B} X\left[t_{1}\right]+N_{o}
\end{aligned}
$$

The SNR at the relay link is Equation (24):

$$
\rho_{\mathrm{RL}}=\frac{\mathrm{P}_{\mathrm{i}}\left|\mathrm{H}_{\mathrm{A}}\right|^{2}}{\mathrm{~N}_{\mathrm{o}}}
$$

The SNR at the access link is Equation (25):

$$
\rho_{\text {accese }}=\frac{P_{\mathrm{RN}}\left|H_{B}\right|^{2}}{N_{o}}
$$

The outage probability of these links is defined as Equation (26 and 27):

$$
\begin{aligned}
& \mathrm{P}_{\mathrm{o}, \mathrm{RL}}=\mathrm{P}_{\mathrm{r}}\left(\rho_{\mathrm{RL}}<\rho_{\mathrm{th}}\right) \simeq \frac{\rho_{\text {th }}}{\rho_{\mathrm{RL}}} \\
& \mathrm{P}_{\mathrm{o} \text {,acces }}=\mathrm{P}_{\mathrm{r}}\left(\rho_{\text {access }}<\rho_{\text {th }}\right) \simeq \frac{\rho_{\text {th }}}{\rho_{\text {access }}}
\end{aligned}
$$

The outage probability for a multi-hop link can be expressed as Equation (28):

$$
\mathrm{P}_{\mathrm{o}, \mathrm{MH}}=\frac{\mathrm{N}_{\mathrm{o}} \rho_{\mathrm{th}}}{\mathrm{P}_{\mathrm{i}}\left|\mathrm{H}_{\mathrm{A}}\right|^{2}}+\frac{\mathrm{N}_{\mathrm{o}} \rho_{\mathrm{th}}}{\mathrm{P}_{\mathrm{RN}}\left|\mathrm{H}_{\mathrm{B}}\right|^{2}}
$$

The SNR is affected by the channel environment such as the distance between the transmitter and receiver, the fading state of the channel and noise and interference. Thus, the channel coefficient between the source and the destination can be defined as:

$$
|\mathrm{H}|^{2}=\mathrm{L}(\mathrm{d})^{-\alpha}
$$

where, $L=G_{t} h_{t}^{2} h_{r}^{2},\left(G_{t}, h_{t}\right)$ and $\left(G_{r}, h_{r}\right)$ are the gains and heights of the transmitter and receiver antennas, 
respectively, whereas $\mathrm{d}$ is the distance between the source and destination. $\alpha$ (typically $\in\{2-5\}$ is the pathloss exponent, which is dependent on the environment (Jaafar et al., 2013):

$$
\mathrm{P}_{\mathrm{o}, \mathrm{MH}}=\frac{\mathrm{N}_{\mathrm{o}} \rho_{\mathrm{th}}}{\mathrm{P}_{\mathrm{i}} \mathrm{Ld}_{\mathrm{RN}}^{-\alpha}}+\frac{\mathrm{N}_{\mathrm{o}} \rho_{\mathrm{th}}}{\mathrm{LP}_{\mathrm{RN}}\left(\mathrm{R}-\mathrm{d}_{\mathrm{RN}}\right)^{-\alpha}}
$$

where, the $\mathrm{R}$ is radius of cell and $\mathrm{d}_{\mathrm{RN}}$ is relay location from BS. The optimum location of the relay to all cell boundaries with respect to the SNR of two multi-hop links can be obtained by using the mathematics of convex optimization (Kumaran et al., 2013). Thus, taking the first derivative of Equation (30) with respect to relay location $\left(\mathrm{d}_{\mathrm{RN}}\right)$ and setting it to zero, then Equation (31):

$$
\frac{\Delta \mathrm{P}_{\mathrm{o}, \mathrm{MH}}}{\Delta \mathrm{d}_{\mathrm{RN}}}=\alpha \frac{\mathrm{N}_{\mathrm{o}}}{\mathrm{LP}_{\mathrm{i}}}\left(\mathrm{R}-\mathrm{d}_{\mathrm{RN}}\right)^{(\alpha-1)}-\alpha \frac{\mathrm{N}_{\mathrm{o}}}{\mathrm{LP}_{\mathrm{RN}}} \mathrm{d}_{\mathrm{RN}}^{(\alpha-1)}
$$

We can obtain the optimum location as Equation (32):

$$
\mathrm{d}_{\mathrm{RN}}=\frac{\mathrm{R}\left(\mathrm{LP}_{\mathrm{i}}\right)^{1 /(\alpha-1)}}{\left(\mathrm{P}_{\mathrm{i}} \mathrm{L}\right)^{1 /(\alpha-1)}+\left(\mathrm{LP}_{\mathrm{RN}}\right)^{1 /(\alpha-1)}}
$$

\subsection{Mobility Nodes Scheme}

In the section, we proposed a mobility model with a HD mode. All UEs in vehicle are moving across of cell at different velocities. The performance and impact the group mobility in terms of SNR were analyzed within a two-way relay.

Based on the derived formulas of instantaneous SNR at direct and relay links in Section A, the group mobility for MRN and user has been derived in order to evaluating the system performance and reducing the transmitted power of MRN. Therefore both UEs and MRN are moving as group mobility across BS.

Typically, the instantaneous SNR changes according to environment of channel, such as the distance between the transmitter and receiver and fading state of the channel.

The user in vehicle receives two signals; via direct link and from MRN via relay link, therefore the combined SNR at UE is:

$$
\rho_{\mathrm{UE}, \mathrm{q}}^{\mathrm{com}}=\rho_{\mathrm{UE}, \mathrm{q}}^{\mathrm{DL}}+\rho_{\mathrm{UE}, \mathrm{q}}^{\mathrm{MRN}}
$$

By inserting Equation 29 in Equation 33 the result is Equation (34 and 35):

$$
\begin{aligned}
& \rho_{\mathrm{UE,q}}^{\mathrm{DL}}=\frac{\mathrm{P}_{\mathrm{i}} \mathrm{L}\left(\mathrm{d}_{\mathrm{C}, \mathrm{q}}\right)^{-\alpha}}{\mathrm{N}_{\mathrm{O}}} \\
& \rho_{\mathrm{UE}, \mathrm{q}}^{\mathrm{MRN}}=\frac{\mathrm{P}_{\mathrm{i}} \mathrm{P}_{\mathrm{RN}} \mathrm{L}\left(\mathrm{d}_{\mathrm{A}}\right)^{-\alpha}\left|\mathrm{H}_{\mathrm{k}, \mathrm{q}}\right|^{2}}{\left[\mathrm{P}_{\mathrm{i}} \mathrm{L}\left(\mathrm{d}_{\mathrm{A}}\right)^{-\alpha}+2 \mathrm{P}_{\mathrm{RN}}\left|\mathrm{H}_{\mathrm{k}, \mathrm{q}}\right|^{2}+\mathrm{N}_{\mathrm{O}}\right] \mathrm{N}_{\mathrm{O}}}
\end{aligned}
$$

Intuitively the distance is function of velocity and time so Equation (36 to 39 ):

$$
\begin{aligned}
& \rho_{\mathrm{UE}, \mathrm{q}}^{\mathrm{DL}}=\frac{\mathrm{P}_{\mathrm{i}} \mathrm{L}\left(\mathrm{v}_{\mathrm{UE}} \mathrm{T}_{\mathrm{UE}}\right)^{-\alpha}}{\mathrm{N}_{\mathrm{O}}} \\
& \rho_{\mathrm{UE}, \mathrm{q}}^{\mathrm{MRN}}=\frac{\mathrm{P}_{\mathrm{i}} \mathrm{P}_{\mathrm{RN}} \mathrm{L}\left(\mathrm{v}_{\mathrm{MRN}} \mathrm{T}_{\mathrm{MRN}}\right)^{-\alpha}\left|\mathrm{H}_{\mathrm{k}, \mathrm{q}}\right|^{2}}{\left[\mathrm{P}_{\mathrm{i}} \mathrm{L}\left(\mathrm{v}_{\mathrm{MRN}} \mathrm{T}_{\mathrm{MRN}}\right)^{-\alpha}+2 \mathrm{P}_{\mathrm{RN}}\left|\mathrm{H}_{\mathrm{k}, \mathrm{q}}\right|^{2}+\mathrm{N}_{\mathrm{O}}\right] \mathrm{N}_{\mathrm{O}}} \\
& \mathrm{R}_{\mathrm{UE,q}}^{\mathrm{MRN}}=\frac{1}{2} \log _{2}\left(1+\rho_{\mathrm{UE}, \mathrm{q}}^{\mathrm{MRN}}\right) \\
& \mathrm{R}_{\mathrm{UE,q}}^{\mathrm{com}}=\frac{1}{2} \log _{2}\left(1+\rho_{\mathrm{UE,q}}^{\mathrm{com}}\right)
\end{aligned}
$$

where, $\mathrm{d}_{\mathrm{A}}, \mathrm{d}_{\mathrm{C}, \mathrm{q}}$ is the distance between BS to each MRN and $\mathrm{UE}_{\mathrm{q}}$ respectively, while $\mathrm{V}_{\mathrm{UE}}, \mathrm{T}_{\mathrm{UE}}$ is the velocity and time of $\mathrm{UE}_{\mathrm{q}}$ at direct link, $\mathrm{V}_{\mathrm{MRN}}, \mathrm{T}_{\mathrm{MRN}}$ is the velocity and time of MRN at relay link (i.e., vehicle velocity and time) and $\rho_{\mathrm{UE}, \mathrm{q}}^{\mathrm{MRN}}, \rho_{\mathrm{UE}, \mathrm{q}}^{\mathrm{DL}}$ is SNR of UE within relay link and direct link respectively. $\mathrm{R}_{\mathrm{UE}, \mathrm{q}}^{\mathrm{MRN}}$ is the achievable bit rate through group mobility. Equation (35) explains the impact SNR with variation of velocity for group mobility $\left(\mathrm{MRN}, \mathrm{UE}_{\mathrm{q}}\right)$.

\subsection{Simulation Analysis}

The propagation of a radio wave is a complex and less predictable process if the transmitter and receiver properties are considered in channel environment calculations. The process is subjected by reflection, diffraction and scattering, the intensities of which vary under different environments at different instances (Korowajczuk, 2011).

ATDI simulator was used to demonstrate the mathematical results for relay link improvement therefore the propagation model for this simulator between the nodes can be expressed as the following Equation (40): 


$$
P_{r}=P_{t}+G_{t}+G_{r}-L_{\text {prop }}-L_{t}-L_{r e} \quad[d B]
$$

Where:

$\mathrm{P}_{\mathrm{t}} \quad=$ Indicates the power at the transmitter and

$\mathrm{P}_{\mathrm{r}} \quad=$ The power at the receiver

$\mathrm{Lt}$ and $\mathrm{L}_{\mathrm{re}}=$ Express the feeder losses

$\mathrm{L}_{\text {prop }} \quad=$ The total propagation loss formulated as Equation (41):

$\mathrm{L}_{\text {prop }}=\mathrm{L}_{\text {fsd }}+\mathrm{L}_{\mathrm{d}}+\mathrm{L}_{\text {sp }}+\mathrm{L}_{\text {gas }}+\mathrm{L}_{\text {rain }}+\mathrm{L}_{\text {clut }}$

Where:

$\mathrm{L}_{\mathrm{fsd}}=$ Free space distance loss

$\mathrm{L}_{\mathrm{d}} \quad=$ Diffraction loss

$\mathrm{L}_{\mathrm{sp}}=$ Sub path loss

$\mathrm{L}_{\text {gas }}=$ Attenuation caused by atmospheric gas

$\mathrm{L}_{\text {rain }}=$ Attenuation caused by hydrometeor scatter and

$\mathrm{L}_{\mathrm{clu}} \mathrm{t}=$ Cutter attenuation

This equation explains the link budget. The link budget is determined by all the gains and losses in the path, which is opposite the transmitted signal to reach the receiver. A link is created by three related communication entities: Transmitter, receiver and a channel between them. The medium introduces losses caused by suction in the received power, as shown in Fig. 3.

\subsection{Power-Balancing Algorithm of MR in LTE- A Cellular Networks}

The SNR at Equation (36 and 37) depends on the transmitted power and path loss between both transmitter and receiver, so, the proposed algorithm is balanced and controlled on the transmitted power of MRN over cell radius to achieve the required SNR and throughput at the users with mitigate the consumption in transmitted relay power.

Typically the coverage distribution close to BS is best than boundaries, therefore no need to consume additional power when the vehicle (i.e., train, bus, metro) pass near BS where there is a good SNR as shown in Fig. 4. The proposed algorithm depends on this idea as explained in Fig. 5.

Two constrain are proposed in algorithm:

$$
\begin{aligned}
& \min \text { imize } \mathrm{P}_{\mathrm{RN}} \\
& \text { subject } 0<\mathrm{P}_{\mathrm{RN}} \leq \mathrm{P}_{\max } \\
& \text { aa }<\rho_{\mathrm{UE}, \mathrm{q}} \leq \rho_{\max } \\
& \rho_{\mathrm{UE}, \mathrm{q}} \geq \rho_{\mathrm{th}}
\end{aligned}
$$

where, $\rho_{\mathrm{th}}, \rho_{\max }$ is the threshold and maximum required SNR at the UE.

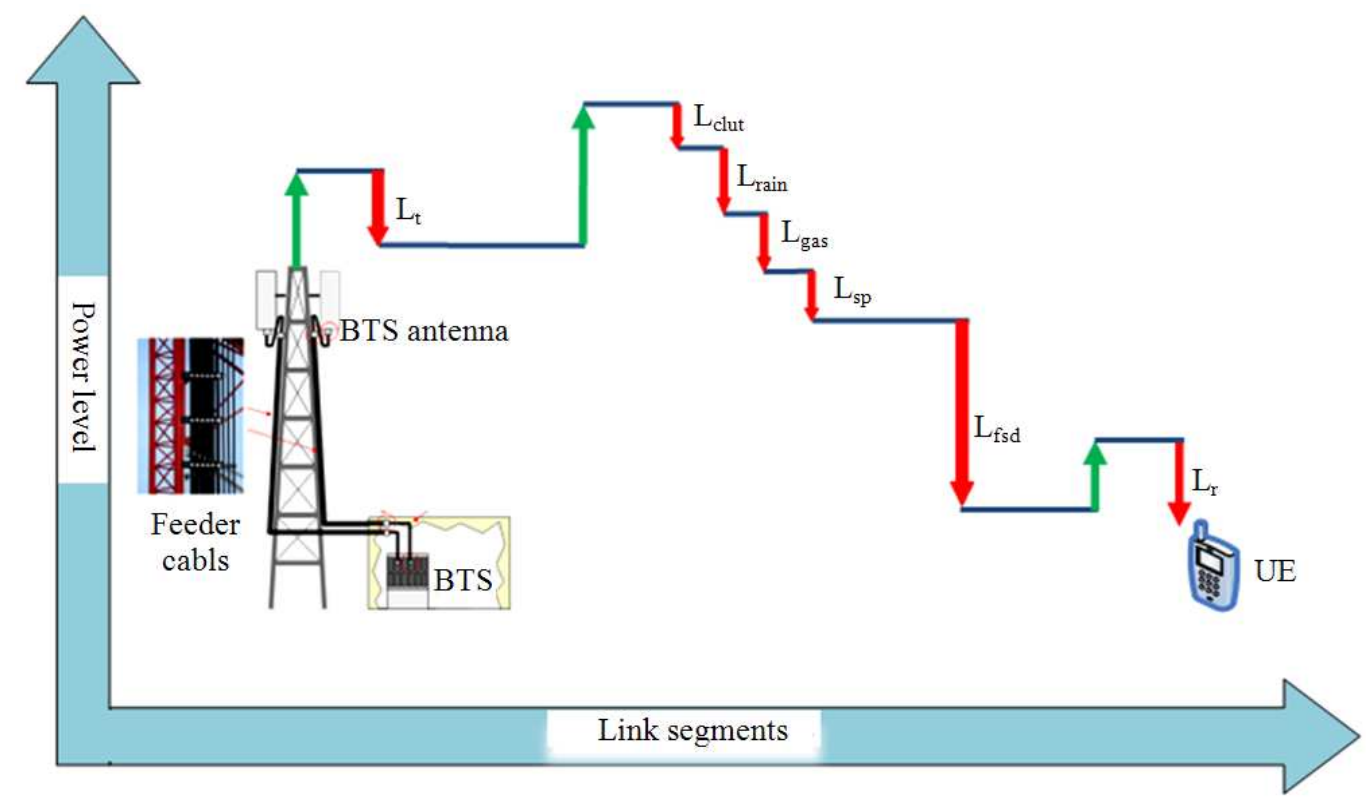

Fig. 3. Link budget scheme 
Jaafar A. Aldhaibani et al. / Journal of Computer Science 10 (6): 1051-1061, 2014

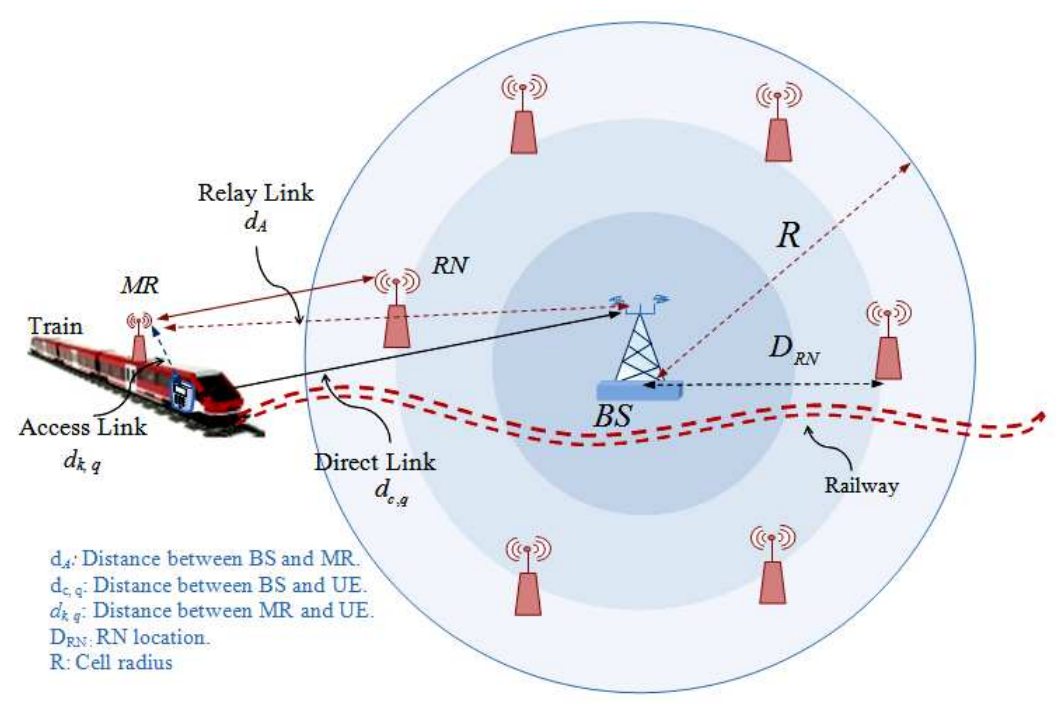

Fig. 4. Train travelling across a one cell size

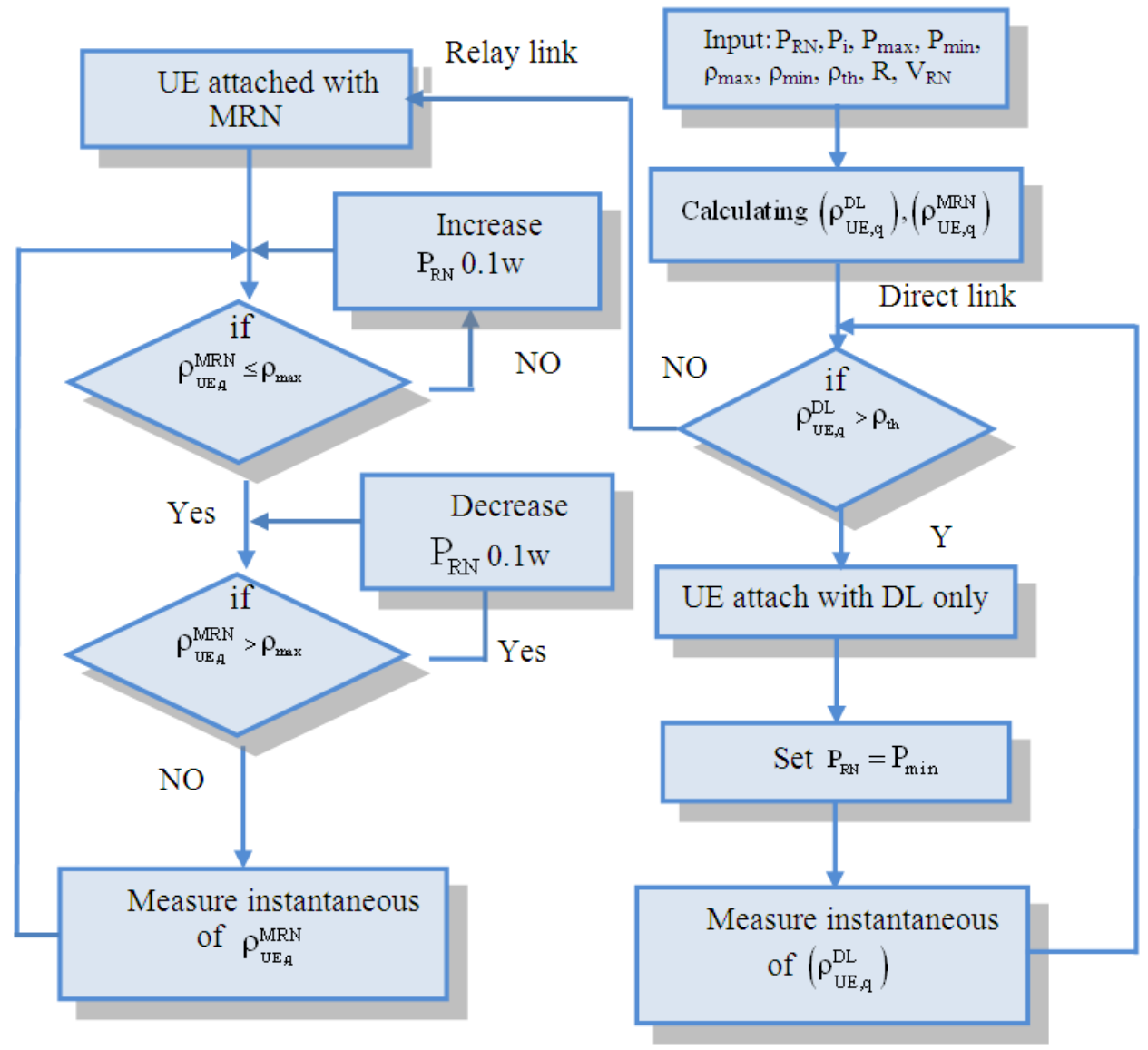

Fig. 5. Flowchart of proposed balancing power algorithm 


\section{RESULTS AND DISCUSSION}

In this section, we present the numerical results of the two scenarios of FRN and group mobility of MRN which are formulated in sections 2 and section 3 . The system parameters were chosen based on Table 1 (3GPP, 2010). Figure 6 shows the bit rate at the downlink versus the SNR at the direct and multi-hop links. The multi-hop link enhanced and increased the bit rate and SNR at the downlink than direct transmission, That's where the relay strengthens the signal transmitted to the user as shown in Fig. 6.

Figure 7 illustrates the received signal strength at user with variation distance from $\mathrm{BS}$. The proposed optimal location of FRN is $68 \%$ from cell radius. This location achieved the enhancing in received signal strength from -87 to $-65 \mathrm{dBm}$, which provides increasing the number of active users at cell edge region as shown in Fig. 7.

The results in Fig. 8 explain the transmitted power saving for MRN when moves across cell size, where there is saving power nearly $60 \%$ without deploy FRN and nearly $75 \%$ after deployment six relays each one with (5) watt at distance $68 \%$ from cell radius (i.e., $1700 \mathrm{~m}$ from BS).

Figuer 9 explains the throughput enhancement at users in vehicle with different velocities of vehicle. This figure demonstrates the enhancement in throughput at users with FRN deployment around central BS. On other hand this enhancing will be better with using MRN above vehicle. However, increasing the velocity of vehicle reduces throughout in group mobility as illustrated in Fig. 9.

The coverage area distribution over real map with terrains is illustrated in Fig. 10. by using ATDI Radio planning software with $20 \mathrm{~m}$ map resolution, where is clear that the coverage area at the centre is better than cell boundary, also the improvement in the coverage area by deployment six FRN at $1700 \mathrm{~m}$ from BS, near the cell edge as shown in Fig. 10.

Table 1. Simulation parameters

\begin{tabular}{ll}
\hline Parameters & Specifications \\
\hline Carrier frequency & $2 \mathrm{G}$ \\
Band width & $2 \mathrm{M}$ \\
Number of BS & 1 \\
Antenna height of the BS & $25(\mathrm{~m})$ \\
BS antenna gain & $17 \mathrm{dBi}$ \\
Max. Tx. power of BS & $46 \mathrm{dBm}$ \\
Path loss exponent $(\alpha)$ & 3.7 \\
Number of FRNs & $1-6$ \\
Antenna height of the relay & $3 \mathrm{~m}$ (above train or bus) \\
& for MRN and 25 m for FRN \\
RN-UE antenna gain & $5 \mathrm{dBi}$ \\
RN-BS antenna gain & $7 \mathrm{dBi}$ \\
Noise figure of RN & $5 \mathrm{~dB}$ \\
Antenna height of the UE & $1.5 \mathrm{~m}$ (not mobility) \\
Antenna gain of UE & $0 \mathrm{~d} \mathrm{Bm}$ \\
Noise figure of UE & $6 \mathrm{~dB}$ \\
$\rho_{\text {th }}$ & $30 \mathrm{~dB}$ \\
$\rho_{\max }$ & $45 \mathrm{~dB}$ \\
$\mathrm{P}_{\mathrm{RN}, \max }$ & $40 \mathrm{dBm}, 10 \mathrm{w}$ \\
\hline
\end{tabular}

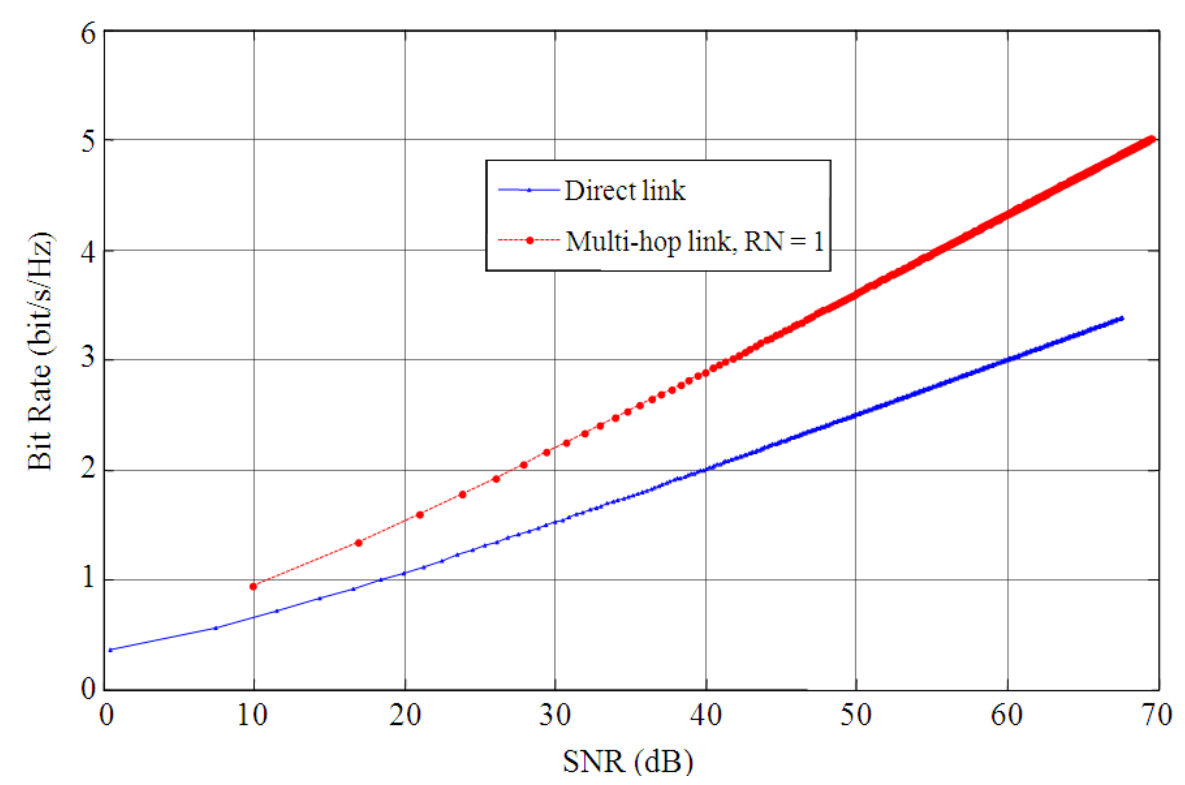

Fig. 6. Bit rate and SNR enhancements between direct and relay links 
Jaafar A. Aldhaibani et al. / Journal of Computer Science 10 (6): 1051-1061, 2014

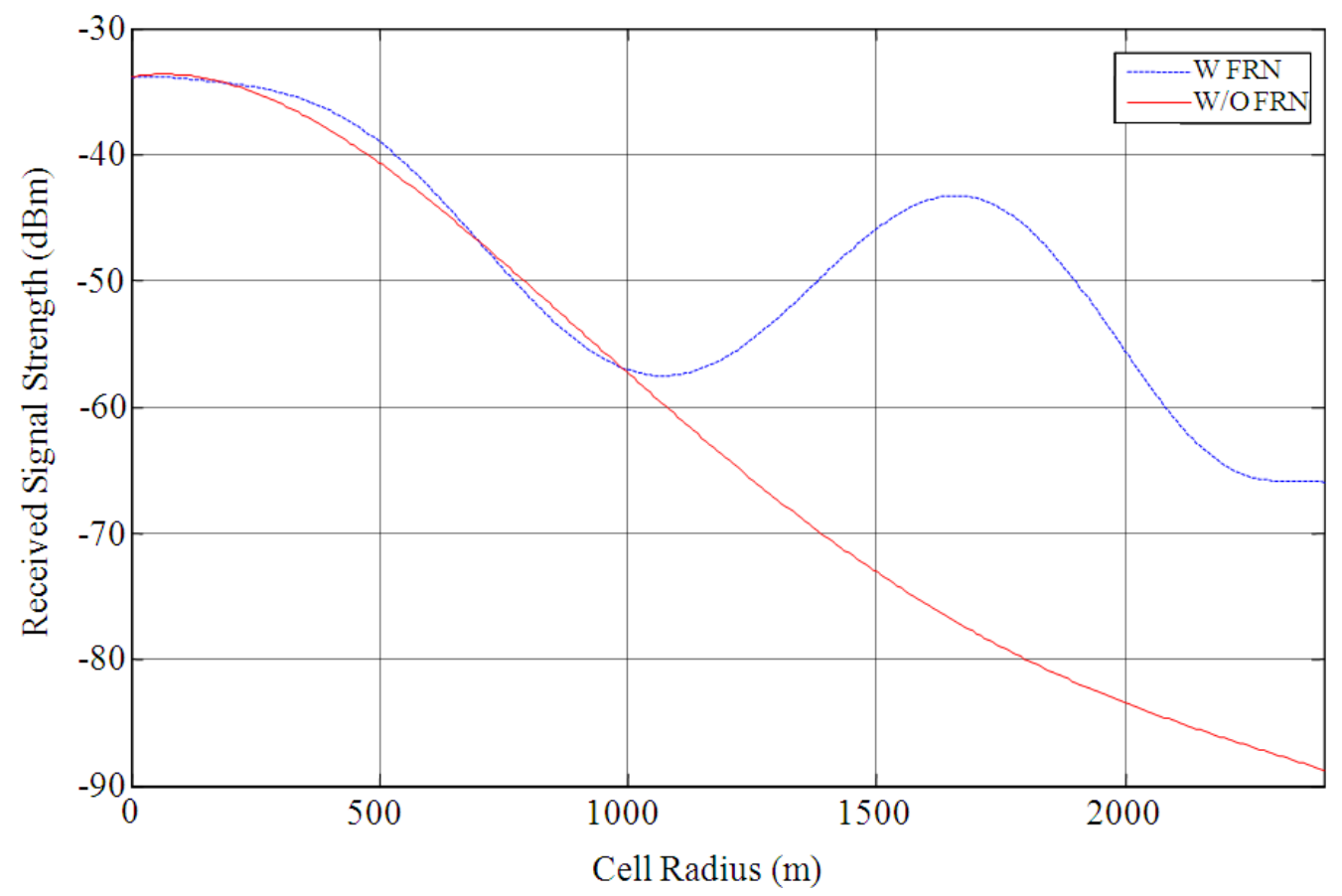

Fig. 7. Improvment in received signal strength for proposed FRN Location

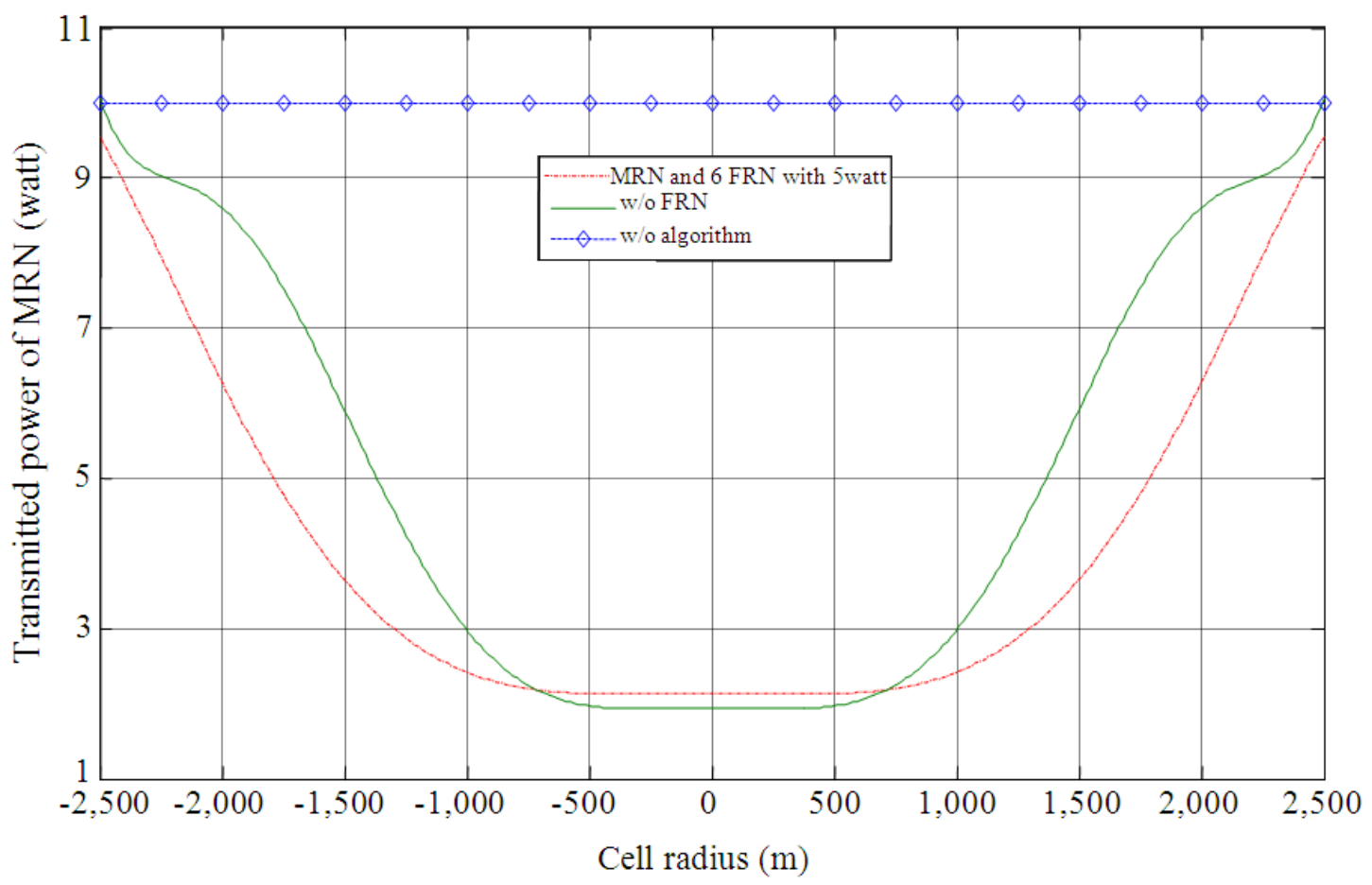

Fig. 8. Reducing the power consumption of MRN 


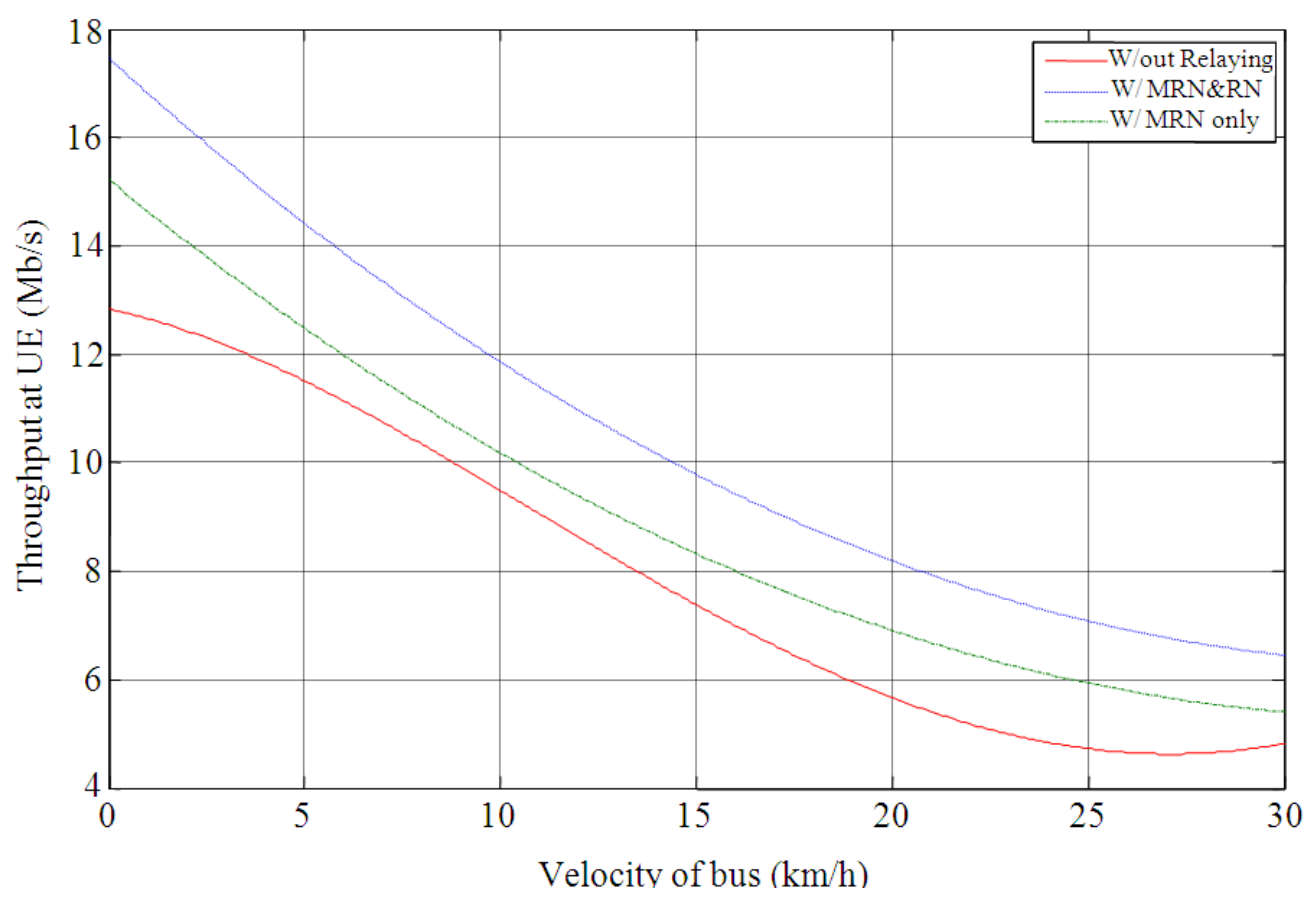

Fig. 9. Throughput enhancement with changing velocity of vehicle

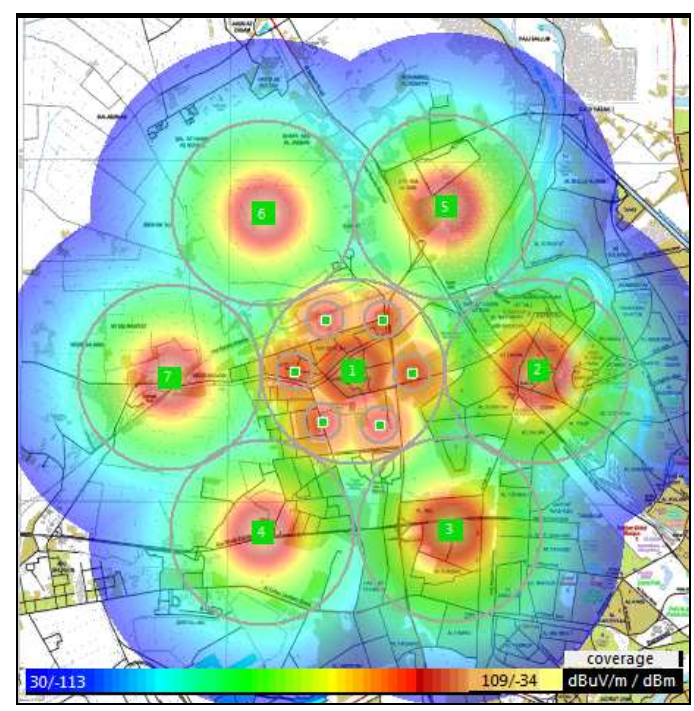

Fig. 10. Coverage extension of downlink signal distribution of BS and six FRN deployed around BS within first tier (six BSs around main BS)

\section{CONCLUSION}

In this study, we introduced performance analyzes two scenarios for FRNs and MRN with a half-duplex mode in a cell. We studied the performance of multi-user with FRN deployment with uplink and downlink styles. Moreover, the optimal location of FRN within cell has been derived in order providing maximum achievable rate within cell boundaries. Finally, we proposed a balancing power algorithm for MRN which is balance of 
the transmitted power over cell size to achieve the required SNR and throughput at the users with reducing the consumption transmitted relay power. The numerical results explained there are enhancement in received signal strength and throughput at users after FRN deployment according to proposed location. In addition there is saving nearly $75 \%$ from transmitted power by relay after using proposed algorithm.

\section{REFERENCES}

Bulakci, O., 2012. Multi-hop moving relays for IMTadvanced and beyond. Aalto University School of Electrical Engineering.

Chun, B. and H. Park, 2012. A spatial-domain jointnulling method of self-interference in full-duplex relays. IEEE Commun. Lett., 16: 436-438. DOI: 10.1109/LCOMM.2012.020712.111733

Gandhi, K.I. and P. Narayanasamy, 2011. Mobile element scheduling for efficient data collection in wireless sensor networks: A survey. J. Comput. Sci., 7: 114-119. DOI: 10.3844/jcssp.2011.114.119

Jaafar, A., A. Aldhaibani, R.B. Yahya, R.B. Ahmad and Z.G. Ali, 2013. Effect of relay location on two-way DF and AF relay for multi-user system in LTE-A cellular networks. Proceedings of the IEEE Business Engineering and Industrial Applications Colloquium, Apr. 7-9, IEEE Xplore Press, Langkawi, $\quad$ pp: 380-385. DOI: 10.1109/BEIAC.2013.6560153

Katiyar, H. and R. Bhattacharjee, 2010. Performance of MRC combining multi-antenna cooperative relay network. AEU Int. J. Electron. Commun., 64: 988991. DOI: 10.1016/j.aeue.2009.07.007

Korowajczuk, L., 2011. LTE, WiMAX and WLAN Network Design, Optimization and Performance Analysis. 1st Edn., John Wiley and Sons, Chichester, ISBN-10: 1119970474, pp: 782.
Kumaran, V., S. Rajkumar and S. Thiruvengadam, 2013. Performance analysis of orthogonal frequency division multiplexing based bidirectional relay network in the presence of phase noise. Am. J. Applied Sci., 10: 1335-1344. DOI: 10.3844/ajassp.2013.1335.1344

Peters, S.W. and R.W. Heath, 2009. The future of WiMAX: Multihop relaying with IEEE 802.16j. IEEE Commun. Mag., 47: 104-111. DOI: 10.1109/MCOM.2009.4752686

Prabha, N.A., G.V. Sagar and V. Manikandan, 2014. Migitation of inter cell interference and fading in LTE systems. J. Comput. Sci., 10: 434-442. DOI: 10.3844/jcssp.2014.434.442

Rizinski, M. and V. Kafedziski, 2011. Achievable rates of the amplify-and-forward strategy for the Gaussian relay channel. Proceedings of the 10th International Conference on Telecommunication in Modern Satellite Cable and Broadcasting Services, Oct. 5-8, IEEE Xplore Press, Nis, pp: 501-504. DOI: 10.1109/TELSKS.2011.6143163

Sadek, A.K., Z. Han and K. Liu, 2010. Distributed relayassignment protocols for coverage expansion in cooperative wireless networks. IEEE Trans. Mobile Comput., 9: 505-515. DOI: 10.1109/TMC.2009.132

Siraj, M. and K.A. Bakar, 2012. Minimizing interference in wireless mesh networks based telemedicine system. J. Comput. Sci., 8: 1263-1271. DOI: 10.3844/jcssp.2012.1263.1271

Sui, Y., A. Papadogiannis and T. Svensson, 2012. The potential of moving relays-a performance analysis. Proceedings of the IEEE 75th Vehicular Technology Conference, May 6-9, IEEE Xplore Press, Yokohama pp: 1-5. DOI: 10.1109/VETECS.2012.6240247 